\title{
Integrin av $\beta 6$ and transcriptional factor Ets-1 act as prognostic indicators in colorectal cancer
}

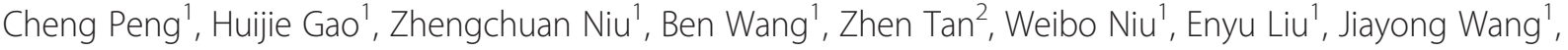 \\ Jiuzheng Sun ${ }^{3}$, Muhammad Shahbaz', Michael Agrez ${ }^{4}$ and Jun Niu ${ }^{1 *}$
}

\begin{abstract}
Background: Both transcriptional factor Ets-1 and integrin av $\beta 6$ play an important role in the development and progression of cancer. The aim of our study was to investigate the expression of Integrin av $\beta 6$ and Ets-1, two proteins' correlation and their clinical significance in colorectal cancerous tissues.

Results: The specimens were arranged into microarray using the immunohistochemistry method to investigate the expression of integrin av $\beta 6$ and transcriptional factor Ets-1 in these tissues. Among the 158 tissue specimens, 36.07\% were positive for av $\beta 6$ expression, and $57.59 \%$ were positive for Ets-1 expression. There were obvious statistical differences existed regarding differentiation, $\mathrm{N}$ stage, $\mathrm{M}$ stage and TNM stage between av $\beta 6$ and Ets-1 positively and negatively expressing tumors. The correlation analysis confirmed the expression of av $\beta 6$ and Ets-1 were positively correlated in colorectal cancer. The Kaplan-Meier survival analysis showed that patients who were both av $\beta 6$ and Ets-1 positive relapsed earlier than those who were both av $\beta 6$ and Ets-1 negative; and the former group had much shorter survival time than the latter. And Cox model indicated that av $\beta 6$ and Ets-1 were the independent prognostic factors $(R R=2.175, P=0.012$ and $R R=3.903, P<0.001)$.

Conclusions: The expression of av $\beta 6$ and Ets-1 were positively correlated, and their expression degrees were associated with the differentiation, $N$ stage, $M$ stage and TNM stage of the tumors. Hence, the combination of av $\beta 6$ and Ets-1 can be used as a prognostic marker in colorectal cancer, especially for the early stage.
\end{abstract}

\section{Introduction}

Colorectal Cancer (CCR) is the most frequent gastrointestinal malignant tumor in the world. According to an estimate of International Agency for Research on Cancer (IARC), there will be about 1.2 million new colorectal patients all over the world every year, and the mortality rate will account for about $8 \%$ of all malignancies [1]. Generally, the CCR occurs more frequently in developed countries. The number of CCR incidence and mortality rates increased a lot in China in the past few years [2]. From 2006 to 2009, the CCR became the 3rd prevalent and 5th most malignant among the entire malignant tumor in China. Therefore, CCR seriously affected the human health [3].

\footnotetext{
* Correspondence: junniu120@163.com

'Department of Hepatobiliary Surgery, QiLu Hospital, Shandong University, Jinan, Shandong, China

Full list of author information is available at the end of the article
}

$\alpha v \beta 6$ is a special subtype of integrin that is expressed in epithelial cells only, and its major ligand is fibronectin (FN). In normal epithelial cells, the expression of $\alpha v \beta 6$ is rare and can hardly be detected [4], but it increases substantially in response to injury and/or inflammation, or in epithelial tumors [5]. Our previous studies show that the de novo expression of the $\alpha \mathrm{v} \beta 6$ integrin has been shown to modulate several processes in colon carcinoma cells, including cell adhesion and spreading on fibronectin, proliferation within collagen gels, tumor growth, cell apoptosis and matrix metalloproteinase (MMPs) secretion [6,7]. We also have suggested that the $\alpha v \beta 6$ integrin is a prognostic indicator of gastric carcinoma, and $\alpha v \beta 6$ would be a useful index to direct early therapy in order to prevent the spread of cancer [8].

Ets-1 is a kind of transcription factor which is present in species ranging from sponges to human. All family members contain an approximately 85 amino acid DNA binding domain, designated as the Ets domain. Ets-1 
proteins bind to special purine-rich DNA sequences with a core motif of GGAA/T, and transcriptionally regulate in a number of viral and cellular genes. Thus, Ets proteins are an important family of transcription factors that control the expression of genes which are critical for several biological processes, including cellular proliferation, differentiation, development, transformation, and angiogenesis [9-11].

Although, many studies have been conducted about finding molecular markers as prognostic indicators for the malignant biological behavior of CCR; there is still a demand to find indicators or its combinations regarding the CCR development and progression. Since many papers have shown that both integrin $\alpha v \beta 6$ and transcription factor Ets-1 participate in the regulation of malignant tumor biological behavior, therefore we performed the immunohistochemical assessment of integrin $\alpha v \beta 6$ and transcription factor Ets-1. We expected these markers or their combinations would become the prognostic indicators in CCR.

\section{Results}

\section{Follow up}

All the specimens can be used to assess the expression of integrin $\alpha v \beta 6$ and transcriptional factor Ets-1. 5-year follow-up was conducted among all the 158 patients, and the follow-up rate was $100 \%$. Among these, 71 (44.9\%) were confirmed cancer specific death within 5 years of prognosis and 87 (55.1\%) were censored as their case follow up was discontinued or patients were alive beyond 60 months or died of reasons other than colon cancer.115 patients $(72.8 \%)$ relapsed from cancer during 5-year follow-up, and 43 (27.2\%) were censored. Follow-up based on patient's history, physical examination, complete blood count, liver function tests, tumor markers monitoring, ultrasound scan of the abdomen every 3 months, abdominal pelvic CT scans and colonoscopy every 6 months. Patients with high-risk factors were encouraged to take adjuvant chemotherapy. Patients with liver metastasis tumor accepted the radiofrequency ablation (RFA) or super $\gamma$ knife radiotherapy. 87 patients received fluorouracil-based adjuvant chemotherapy, and 28 patients received the RFA or radiotherapy.

\section{Expression of $a v \beta 6$ and Ets- 1 in the tissue specimens and clinical character}

In the 158 tissue specimens, 57 (36.07\%) were positive for $\alpha v \beta 6$ expression, and 91 (57.59\%) were positive for Ets-1 expression. Clinicopathological features and $\alpha v \beta 6$ \& Ets- 1 expression of all specimens were expounded in details in Table 1. And the expression levels of $\alpha v \beta 6$ and Ets- 1 in 10 samples of normal colon mucosa were both negative. A following analysis showed that there was no evidence of a statistical difference between $\alpha v \beta 6$ or Ets- 1 positive and negative tumors regarding age, gender, location, tumor size, Duke's phase, T stage, and histopathological type, but significant statistical differences existed regarding differentiation, $\mathrm{N}$ stage, $\mathrm{M}$ stage and TNM stage. $\alpha v \beta 6$ and Ets1staining patterns in the tissue specimens are shown in Figure 1. High $\alpha v \beta 6$ expression was detected at the invading edge of the tumor, and staining was observed predominantly in the cell membrane. Ets-1 mainly exhibited a nuclear and cytoplasmic immunostaining in tumor cells.

\section{Correlation between the av $\beta 6$ and Ets-1expression}

In the 158 tissue specimens, 101 (63.92\%) were negative for $\alpha v \beta 6$ expression, 30 (18.99\%) were low positive for $\alpha v \beta 6$ expression, 27 (17.09\%) were high positive for $\alpha v \beta 6$ expression; 67 (42.41\%) were negative for Ets-1 expression, 30 (37.34\%) were low positive for Ets-1 expression, 32 (20.25\%) were high positive for Ets-1 expression. The expression of $\alpha v \beta 6$ and Ets-1 were positively correlated $(r=0.711, P=0.000)$, Specific data was shown in Table 2 .

\section{Expression of both av $\beta 6$ and Ets-1 predicts relapse and patients survival}

According to the expression of $\alpha v \beta 6$ and Ets-1, all patients were divided into four categories: both $\alpha v \beta 6$ and Ets-1 positive group (Group 1), $\alpha v \beta 6$ positive with Ets-1 negative group (Group 2), $\alpha v \beta 6$ negative with Ets-1 positive group (Group 3), and both $\alpha v \beta 6$ and Ets-1 negative group (Group 4), respectively. The Kaplan-Meier survival analysis showed that patients who were both $\alpha v \beta 6$ and Ets- 1 positive relapse earlier $(32.59 \pm 2.37)$ than those who were in Group $2(43.82 \pm 2.57)$, Group 3 (46.68 \pm 1.83$)$, and Group $4(53.30 \pm 1.10)(P=0.000)$. And patients who were in either $\alpha v \beta 6$ or Ets-1 positive (Group 2 and 3) also relapsed earlier than those who were both $\alpha v \beta 6$ and Ets-1 negative $(P<0.0001)$ (Figure 2$)$. Likewise, the Kaplan-Meier survival analysis showed that patients who were both $\alpha v \beta 6$ and Ets- 1 negative live longer $(56.82 \pm 0.95)$ than those who were both $\alpha v \beta 6$ and Ets1 positive $(46.23 \pm 1.71)$, and those who were in Group $2(52.31 \pm 2.41)$ or Group $3(53.62 \pm 1.71)(P<0.0001)$. And patients who were in Group 2 or Group 3 live shorter than those who were both $\alpha v \beta 6$ and Ets-1 negative $(P<0.0001)$ (Figure 3$)$.

\section{Univariate and multivariate analysis for prognosis of patients with colon cancer}

The Cox proportional hazards regression model were used to conduct Univariate and multivariate data analyses to determine the prognostic value of $\alpha v \beta 6$ and Ets- 1 expression. Positive expression of $\alpha v \beta 6$ and Ets-1, as well as senior grade of $\mathrm{N}$ stage, $\mathrm{M}$ stage, and TNM stage were the factors to predict a poor prognosis in univariate analysis (Shown in Table 3 ). Then the variables with $\mathrm{P}<0.05$ were chosen to conduct multivariate analysis, we revealed that positive expression of $\alpha v \beta 6$ and Ets-1 were unfavorable 
Table 1 Patients characteristic and the expression of intgerin av $\beta 6$ and transcriptional factor Ets-1

\begin{tabular}{|c|c|c|c|c|c|c|c|c|c|}
\hline \multirow[t]{2}{*}{ Factor } & \multirow[t]{2}{*}{$\mathbf{N}$} & \multicolumn{3}{|c|}{$\operatorname{av} \beta 6$} & \multirow[t]{2}{*}{$P$} & \multicolumn{3}{|c|}{ Ets-1 } & \multirow[t]{2}{*}{$P$} \\
\hline & & Negative & Low & High & & Negative & Low & High & \\
\hline \multicolumn{10}{|l|}{ Age } \\
\hline$<60 Y$ & 62 & 34 & 16 & 12 & & 27 & 23 & 12 & \\
\hline$>60 Y$ & 96 & 67 & 14 & 15 & 0.127 & 40 & 36 & 20 & 0.964 \\
\hline \multicolumn{10}{|l|}{ Gender } \\
\hline Male & 115 & 75 & 20 & 20 & & 49 & 43 & 23 & \\
\hline Female & 43 & 26 & 10 & 7 & 0.705 & 18 & 16 & 9 & 0.991 \\
\hline \multicolumn{10}{|l|}{ Location } \\
\hline Colon & 127 & 83 & 24 & 20 & & 55 & 48 & 24 & \\
\hline Rectum & 31 & 18 & 6 & 7 & 0.641 & 12 & 11 & 8 & 0.688 \\
\hline \multicolumn{10}{|l|}{ Tumor size } \\
\hline$<2 \mathrm{~cm}$ & 15 & 9 & 4 & 2 & & 6 & 6 & 3 & \\
\hline $2 \sim 5 \mathrm{~cm}$ & 109 & 70 & 22 & 17 & & 47 & 40 & 22 & \\
\hline$>5 \mathrm{~cm}$ & 34 & 22 & 4 & 8 & 0.624 & 14 & 13 & 7 & 0.999 \\
\hline \multicolumn{10}{|l|}{ Differentiation } \\
\hline Well & 28 & 22 & 4 & 2 & & 15 & 9 & 4 & \\
\hline Moderate & 93 & 67 & 16 & 10 & & 41 & 37 & 15 & \\
\hline Poor & 27 & 11 & 8 & 8 & & 10 & 10 & 7 & \\
\hline Unknown & 10 & 1 & 2 & 7 & 0.000 & 1 & 3 & 6 & 0.035 \\
\hline \multicolumn{10}{|l|}{ Duke's phase } \\
\hline$A+B$ & 92 & 59 & 20 & 13 & & 40 & 34 & 18 & \\
\hline$C+D$ & 66 & 42 & 10 & 14 & 0.366 & 27 & 25 & 14 & 0.942 \\
\hline \multicolumn{10}{|l|}{ T stage } \\
\hline $\mathrm{T} 1$ & 48 & 31 & 8 & 9 & & 19 & 18 & 11 & \\
\hline $\mathrm{T} 2$ & 70 & 42 & 16 & 12 & & 28 & 30 & 12 & \\
\hline T3 & 33 & 24 & 4 & 5 & & 18 & 9 & 6 & \\
\hline T4 & 7 & 4 & 2 & 1 & 0.851 & 2 & 2 & 3 & 0.470 \\
\hline \multicolumn{10}{|l|}{$\mathrm{N}$ stage } \\
\hline No & 68 & 56 & 6 & 6 & & 39 & 21 & 8 & \\
\hline N1 & 67 & 33 & 18 & 16 & & 22 & 28 & 17 & \\
\hline N2 & 23 & 12 & 6 & 5 & 0.001 & 6 & 10 & 7 & 0.015 \\
\hline \multicolumn{10}{|l|}{ M stage } \\
\hline MO & 130 & 93 & 24 & 13 & & 60 & 52 & 18 & \\
\hline M1 & 28 & 8 & 6 & 14 & 0.000 & 7 & 7 & 14 & 0.000 \\
\hline \multicolumn{10}{|l|}{ TNM stage } \\
\hline$|\&| \mid$ & 66 & 56 & 5 & 5 & & 32 & 23 & 11 & \\
\hline III & 64 & 37 & 19 & 8 & & 28 & 29 & 7 & \\
\hline IV & 28 & 8 & 6 & 14 & 0.000 & 7 & 7 & 14 & 0.000 \\
\hline \multicolumn{10}{|l|}{ Histopathological type } \\
\hline Tubular adenocarcinoma & 134 & 85 & 26 & 23 & & 58 & 52 & 24 & \\
\hline Mucinous adenocarcinoma & 15 & 10 & 2 & 3 & & 6 & 4 & 5 & \\
\hline Other type & 9 & 6 & 2 & 1 & 0.955 & 3 & 3 & 3 & 0.826 \\
\hline
\end{tabular}



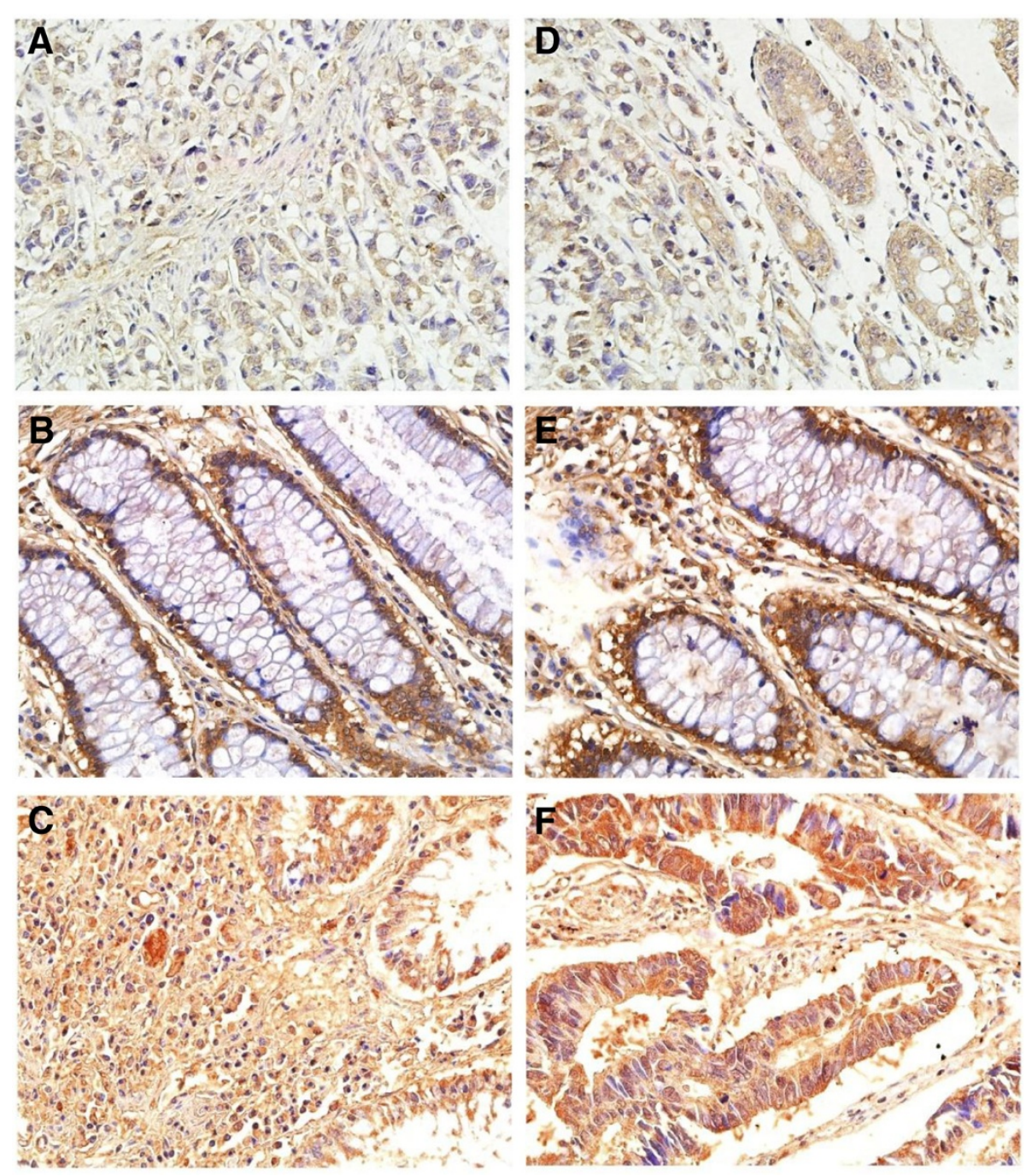

Figure 1 Images of av $\beta 6$ and Ets-1 immunohistochemistry staining in human colorectal cancer samples. av $\beta 6$ staining was observed predominantly in the cell membrane. $\mathbf{A}-\mathbf{C}$ the immunohistochemistry photomicrographs of integrin av $\beta 6$. $\mathbf{A}$ : integrin av $\beta 6$ weak staining, $\mathbf{B}$ : integrin av $\beta 6$ moderate stainning, $\mathbf{C}$ : integrin av $\beta 6$ high staining; Ets-1 mainly exhibited a nuclear and cytoplasmic immunostaining in tumor cells. D-F the immunohistochemistry photomicrographs of transcriptional factor Ets-1. D: Ets-1 weak staining, E: Ets-1 moderate staining, F: Ets-1 high staining.

independent prognostic factors $(\mathrm{RR}=2.175, P=0.012$ and $\mathrm{RR}=3.903, P<0.001$, respectively) (Shown in Table 3 ).

\section{Discussion}

Colorectal cancer has a higher morbidity and mortality in the world. Despite improvements made in screening

Table 2 Expression correlation of intgerin av $\beta 6$ and transcriptional factor Ets-1

\begin{tabular}{lccc}
\hline av $\beta 6$ & \multicolumn{3}{c}{ Ets-1 expression } \\
\cline { 2 - 4 } expression & Negative & Low & High \\
\hline Negative & 64 & 35 & 2 \\
Low & 2 & 19 & 9 \\
High & 1 & 5 & 21 \\
\hline
\end{tabular}

and treatments during the past years, the clinical outcome of colon cancer remains unsatisfactory. Understanding the molecular mechanism of tumorigenesis would contribute to treatment of patients with this disease [12].

The data in the present study indicated that the total expression percentage of integrin $\alpha \mathrm{v} \beta 6$ and Ets- 1 in colorectal cancer was $36.07 \%$ and $57.59 \%$ respectively. The expression level of $\alpha \mathrm{v} \beta 6$ and Ets- 1 was associated with the differentiation, $\mathrm{N}$ stage, $\mathrm{M}$ stage and TNM stage of the tumors. Correlation analysis showed that the expression of $\alpha \mathrm{v} \beta 6$ and Ets- 1 were positively correlated, and their strong stains were always detected at the invading edge of the tumor, weak or no stain always in the center of the tumor. These findings about integrin 


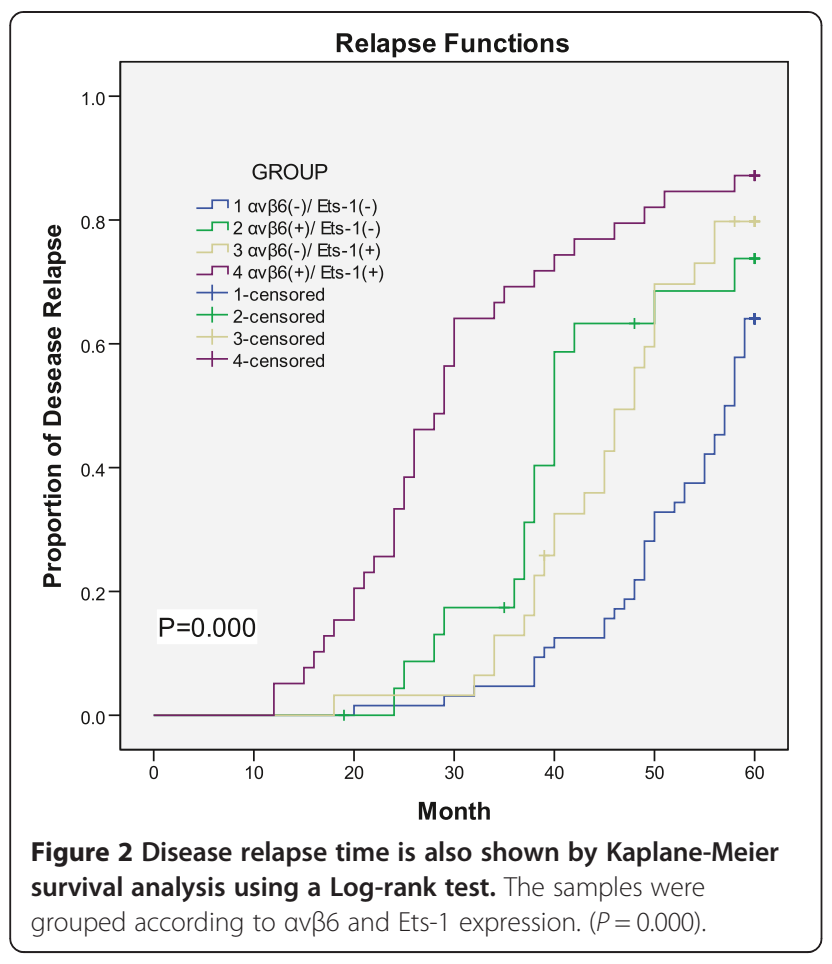

$\alpha v \beta 6$ expression were similar with our previous study in gastric carcinoma [8], and Ets-1 expression pattern and its role look like Ito [13]. The phenomenon above could be explained as following: High cell density in tumor induces integrin $\alpha v \beta 6$ and Ets- 1 expression, which promote MMP-9 secretion for colon cancer cells,increasing

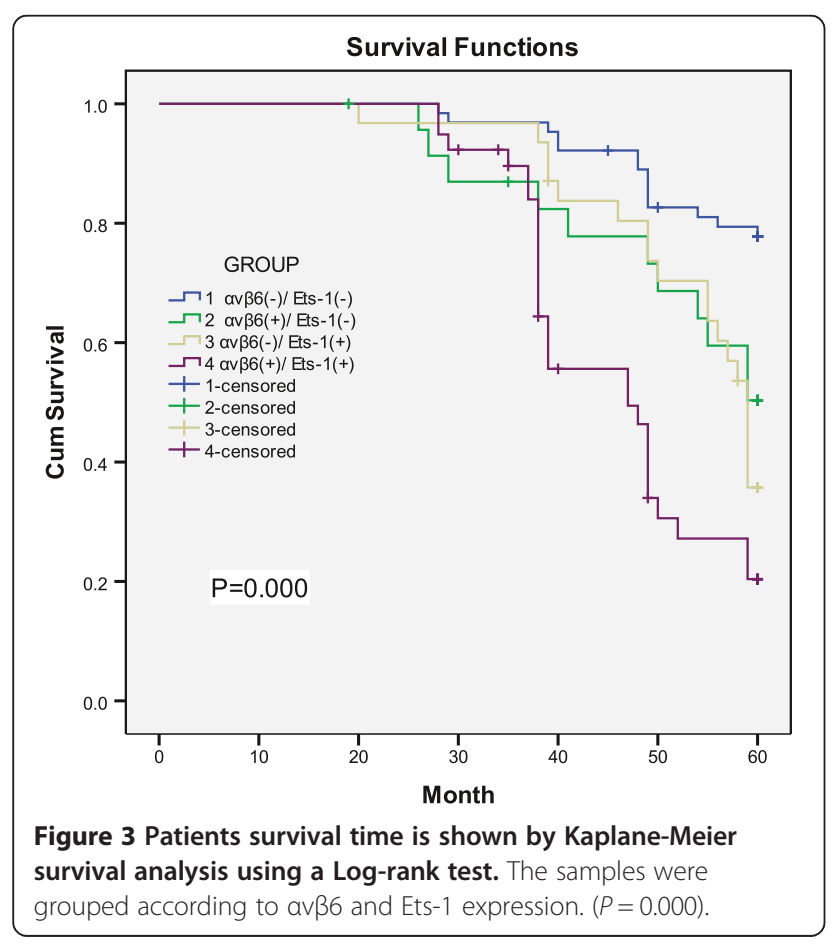

the degradation of extracellular matrix (ECM), which constitutes the molecular biological basis for a selfperpetuating system of tumor invasive growth in colon cancer progression.

In the present study, survival analysis showed that patients who were both $\alpha v \beta 6$ and Ets- 1 positive relapsed earlier than others, and their survival time was also obviously shorter. Based on these data, we confirmed that the concomitant expression of $\alpha v \beta 6$ and Ets- 1 in colorectal cancer cells could be used as an independent predictor to determine early relapse, metastases and prognosis in CRC patients. The important conclusion of this study is similar with our previous study [14] and Zsuzsanna [15].

We have previously shown a direct linkage between ERK2 and the cytoplasmic domain of $\beta 6$, and have delineated the binding domain for ERK2 within the cytoplasmic tail of the 36 -integrin subunit, ${ }^{746}$ EAERSKAKWQTGTNPLYRG $^{764}$ (the ERK2 binding sequence is italic) [16]. Through this physical interaction, integrin $\alpha v \beta 6$ transmitted a growth-enhancing signal to cancer cells. In vivo studies of colon cancer xenografts expressing a 36 mutant lacking the ERK2 binding domain indicated that deletion of the $\beta 6$-ERK2 binding motif greatly compromised tumor growth. Taken all the factors into consideration, these results suggested that tumor growth was, at least in part, dependent on direct $\alpha v \beta 6$-ERK binding. Meanwhile, we also have known that in colorectal cancer cells $\alpha v \beta 6$-ERK2 direct linkage could increase the phosphorylation level of ERK2, and ERK2 conformation would be changed as soon as binding with $\alpha v \beta 6$. To some extent, this process helped ERK2 to be phosphorylated easily, and protected phosphorylated ERK2 not to be dephosphorylated [17]. The effective targets of phosphorylated-ERK2 were localized in the nucleus. Unfortunately, the nuclear factors which could be regulated by phosphorylated-ERK2 still remained unclear.

Park showed that the expression of Ets-1 has intimate correlation with tumor cell invasion and metastasis. Ets-1 and MMPs co-expressed in colon cancer and other malignant tumor, and its expression degree would be increased with tumor invasion and metastasis extent accordingly, but its expression was very low in benign and non-invasive tumor [18]. Hashiya confirmed that Ets-1 played an important role in promoting the tumor angiogenesis through regulating angiogenesis factor, such as VEGF, Ang2, and so on [11]. Other studies showed that Ets-1 could induce the tumor cell apoptosis through regulating cell cycle via changing the expression of p21, p53, cyclinD1, c-Fos in tumor cells [19-21].

In this study, we confirmed that the $\alpha v \beta 6$ and Ets1expressions were positively correlated, and they always expressed in invading edge of the tumor, and their expression degree were associated with the 
Table 3 Univariate and multivariate analysis of association of clinicopathologic features with survival time

\begin{tabular}{l} 
Variable \\
\hline Age at diagnos \\
Gender \\
Male \\
Female \\
Location \\
Colon \\
Rectum \\
Tumor size \\
$<2 \mathrm{~cm}$ \\
$2 \sim 5 \mathrm{~cm}$ \\
$>5 \mathrm{~cm}$
\end{tabular}

Duke's phase

$\begin{array}{cc}A+B & 1.000 \text { (Ref.) } \\ C+D & 1.460\end{array}$

T stage

$\begin{array}{ll}\text { T1 } & 1.000 \text { (Ref.) } \\ \text { T2 } & 1938.169 \\ \text { T3 } & 2612.435 \\ \text { T4 } & 3765.785\end{array}$

N stage

$\begin{array}{cc}\text { No } & 1.000 \text { (Ref.) } \\ \text { N1 } & 2.202 \\ \text { N2 } & 1.845\end{array}$

\section{M stage}

$\begin{array}{cc}\text { M0 } & 1.000 \text { (Ref.) } \\ \text { M1 } & 3.430\end{array}$

TNM stage

$\begin{array}{cc}\text { I } & 1.000 \text { (Ref.) } \\ \text { II } & 1.421 \\ \text { III } & 2.697 \\ \text { IV } & 6.005\end{array}$

Differentiation

$\begin{array}{lc}\text { Well } & 1.000 \text { (Ref.) } \\ \text { Moderate } & 1.606 \\ \text { Poor/unknown } & 1.794\end{array}$

Ets-1

\begin{tabular}{lcccccc} 
Negative & 1.000 (Ref.) & - & - & 1.000 (Ref.) & - & - \\
Positive & 4.913 & $2.792,8.645$ & $<0.001$ & 3.903 & $1.945,7.832$ & \\
av $\beta 6$ & & & & & & \\
Negative & 1.000 (Ref.) & - & - & 1.000 (Ref.) & - \\
Positive & 3.775 & $2.324,6.133$ & $<0.001$ & 2.175 & $1.190,3.974$ & 0.012 \\
\hline
\end{tabular}

Univariate analysis

95\% Cl P value

0.583

Relative risk

Multivariate analysis

$95 \% \mathrm{Cl}$

$P$ value

0.953

0.064

0.167

0.260

$\begin{array}{ll}0.798,2.302 & 0.260\end{array}$

$0.877,2.432 \quad 0.146$

0.386

$\begin{array}{ll}0.000,>105 & 0.912 \\ 0.000,>105 & 0.909 \\ 0.000,>105 & 0.905 \\ & 0.010\end{array}$

0.721
1.000(Ref.)
0.697
0.649

$0.261,1.859$

$0.221,1.903$

0.470

$0.921,3.696$

0.084

1.000(Ref.)

$<0.001$

1.998

$0.432,9.235$

0.376

$<0.001$

1.000(Ref.)

0.567

0.108

0.004

1.599

$0.479,5.341$

0.446

$0.804,9.049$

1.846

\#

$0.384,8.887$

0.444

0.257

1.000(Ref.)

0.181

0.103

$0.802,3.216$

$0.889,3.620$

2.175

$1.190,3.974$

0.012

\#: TNM stage IV is linearly dependent on M stage M1. 
differentiation, $\mathrm{N}$ stage, $\mathrm{M}$ stage and TNM stage of the tumors. So we thought that Ets-1 was likely to be the nuclear factor of ERK2. Perhaps, we proposed that integrin $\alpha v \beta 6$ regulated the cancer cell malignant biological behavior through $\alpha v \beta 6$-ERK-Ets-1 signal pathway.

Importantly, Ets-1 could transcriptionally regulate the expression of integrin beta6, which has been reported by Bates et al. [22]. Thus, a signal loop involving Ets-1 and av $\beta 6$ probably exists to play a key role in tumor cellular growth and migration. Of course, our hypotheses need demonstrating in our future work.

We have already demonstrated that $\beta 6$-integrin is associated with chemo resistance in colon cancer, and $\beta 6$-integrin could induce 5-FU resistance through the ERK/MAP kinase pathway and the $\beta 6$-ERK2 direct binding [23]. In our another study, we have also proved that Norcantharidin (NCTD), as an anti-cancer traditional chinese medicine, could decrease $\alpha v \beta 6$ expression and inhibit ERK phosphorylation in HT-29 cells [24]. In the present study, we found combination of $\alpha v \beta 6$ and Ets- 1 could favor colon cancer prognosis. These results indicate $\beta 6$-integrin might be a novel therapeutic target in colon cancer therapy, and it reminded us that if positive $\alpha v \beta 6$ and Ets- 1 were found in patients with colon cancer of early stage, compared with negative, we would take more aggressive chemotherapy, or more frequent reexamination. However, patients in advanced stage have a worse prognosis, whatever aggressive therapy to take. Therefore, we should take earlier diagnosis and treatment of cancer, and different therapy methods could be applied in patients with distinct gene expression patterns.

To Date, based on this study results and other previous conclusions, we think that co-expression of $\alpha \mathrm{v} \beta 6$ and Ets-1 could serve as a significant prognositic indicator for colorectal cancer, and their interaction might play an important role in cancer progression. Therefore, any key molecule in $\alpha v \beta 6-E R K-E t s-1$ signal pathway, or even the potential signal loop, can be used as an attractive therapeutic candidate for CRC. This new study is encouraging. However, further research is needed to confirm the findings and to establish the relationship between the $\alpha v \beta 6$ and Ets- 1 as a significant prognositic indicator for colorectal cancer.

\section{Materials and methods}

\section{Antibodies and reagents}

The mouse anti-human monoclonal antibody 6.2A1 (IgG1) against integrin $\alpha v \beta 6$ was obtained from Biogen (Cambridge, USA), monoclonal antibody A0478 (IgG1) against Ets-1 was obtained from Bio-tech (Sunnyvale, California, USA), and biotinylated rabbit anti-mouse IgG was obtained from Dako (Copenhagen, Denmark).

\section{Human tissue specimens}

158 cases of colorectal carcinoma specimens and endoscopic colon biopsy samples of normal colon mucosa $(\mathrm{n}=10)$ which obtained from January 2006 to June 2008, were selected randomly from Qilu Hospital of Shandong University (Jinan, Shandong Province, China). Those colorectal carcinoma and normal colorectal mucosa specimens were formalin-fixed and paraffinembedded. The informed consent was obtained from all the patients or their relatives. The study complied with the requirements of The Ethics Committee of Qilu Hospital, Shandong University.

\section{Immunohistochemistry}

Immunohistochemistry was performed on 5 micrometer sections of the FFPE routine sections and tissue microarray (TMA) analysis using monoclonal mouse antibodies against $\alpha v \beta 6$ (6.2A1) and Ets-1 (A0478) was applied respectively. The sections were deparaffinized and hydrated, and the heat induced epitope retrieval was performed using Borg decloaking high $\mathrm{pH}$ buffer in the Biocare decloaking chamber. Endogenous peroxidase's activity was blocked with $3 \%$ hydrogen peroxide. The slides were first incubated with an avidin-biotin kit, followed by incubations with the $\alpha v \beta 6$ primary antibody (1:500 dilutions) overnight at $4^{\circ} \mathrm{C}$, streptavidin-horseradish peroxidase, and Betazoid Diaminobenzidine for color development. Negative controls were prepared by using the identical concentration of mouse immunoglobulin IgG1 (Dako). The next day, biotinylated anti-mouse IgG (1:200) was applied to the slides, which were subsequently treated using horseradish peroxidase (HRP)-labelled streptoantibiotin (Dako) for $15 \mathrm{~min}$. The slides were counterstained with Dako Hematoxylin, rinsed with water, and then dehydrated with alcohol and xylene, and coverslipped. Appropriate controls were included. All incubations were done at the room temperature.

Assessment of av $\beta 6$ and Ets-1 scoring in the tissue sections $\alpha v \beta 6$ stain was mainly on the internal surface of the tumor cell membrane. $\alpha v \beta 6$ and Ets-1 stain were evaluated independently by two pathologists who were blinded to patients' prognosis. Disagreements were resolved by discussion in a meeting which was held to obtain the final results. The proportion score represented the estimated fraction of positive staining cells $(0,0 \% ; 1$, $<20 \% ; 2,20 \sim 50 \% ; 3,51 \sim 75 \% ; 4,>75 \%)$. Intensity of the staining: 0 , no staining; 1 , weak staining, pale brown; 2 , moderate staining, brown; 3 , strong staining, dark brown. We took into account both the intensity and the proportion of positive cells to give a semi quantitative estimate of the expression levels of antigen in the tissue core. Added the two scores, the last score of every section was obtained. We defined the staining class 
according to the last score as follows: tumors with a final score $<2$ were designated as negative expression, $2 \sim 4$ as low (weak) expression, and $\geq 5$ as high (strong) expression. Both low and high expressions were graded as $\alpha v \beta 6$ and Ets-1 positive.

\section{Patients and follow-up}

From January 2006 to June 2008, 158 patients who underwent curative resection by the same surgical team for pathologically confirmed colon cancer at the Department of Pathology of Qilu Hospital (Shandong University, China) were divided into three groups (both $\alpha v \beta 6$ and Ets- 1 positive group, both $\alpha v \beta 6$ and Ets-1 negative group, and either $\alpha v \beta 6$ or Ets-1 positive group) to investigate disease relapse and survival time. In our protocol for the follow-ups, all patients were followed every 3 months in the first year and at least every 6 months afterwards. They were examined with regular monitoring of metastasis by abdomen ultrasonography or computed tomography $(\mathrm{CT})$ studies of the peritoneal organs and lymph nodes. New relapse lesions were diagnosed based on the typical image findings from CT scans.

\section{Statistical methods}

Associations between immunohistochemical scores and clinicopathologic variables of tissue specimens were evaluated by $\chi^{2}$ test. Expression correlation of $\alpha v \beta 6$ and Ets-1 was assessed using bivariate correlation analysis by $X^{2}$ test. Disease relapse time was referred to as the time from the date of surgery to colorectal cancer-related disease appearance, including local recurrence, liver metastasis, peritoneal metastasis, significantly elevated tumor markers, and etc. Survival time was measured as the time from the date of surgery to disease-related death, and those who died from other reasons or were still alive when they were last seen were censored. Survival analysis was carried out using the Kaplane-Meier survival and Cox model analysis. $P<0.05$ was considered statistically significant. Graphs showed the mean \pm SD of data from a representative experiment; data were representative of at least three experiments with comparable results.

\section{Competing interests}

The authors declare that they have no competing interests.

\section{Authors' contributions}

NJ was responsible for designing of the study and critical review of manuscript; PC were responsible for designing and performing of the study literature research and manuscript writing; GH, WB, SJ were responsible for data acquisition; NZ, TZ, NW,LE were responsible for data analysis; WJ, MS, MA were responsible for critical review of manuscript. All authors approved the final version of the manuscript.

\section{Acknowledgement}

This study was supported by research grants from the National Natural Sciences Foundation of China (No. 81272653) and from the Shandong Province Outstanding Young Scientists Funds (No. BS2011YY020).

\section{Author details}

'Department of Hepatobiliary Surgery, QiLu Hospital, Shandong University, Jinan, Shandong, China. ${ }^{2}$ Health Science College, The State University of New York -Stony Brook University, Stony Brook, NY, USA. ${ }^{3}$ Department of General Surgery, Jinan Central Hospital, Shandong University, Jinan, Shandong, China. ${ }^{4}$ Newcastle Bowel Cancer Research Collaborative, Hunter Medical Research Institute, John Hunter Hospital and Faculty of Medicine and Health Sciences, The University of Newcastle, Callaghan, NSW, Australia.

Received: 3 April 2014 Accepted: 18 August 2014

Published: 2 September 2014

\section{References}

1. Ferlay J, Shin HR, Bray F, Forman D, Mathers C, Parkin DM: Estimates of worldwide burden of cancer in 2008:GLOBOCAN 2008. Int J Cancer 2010 127:2893-2917.

2. Chen Q, Liu ZC, Cheng LP: An analysis of incidence and mortality of colorectal cancer in China, 2003 2007. China Cancer 2012, 21:179-182.

3. Chen WQ, Zhang SW, Zheng RS: Report of cancer incidence and mortality in China, 2009. China Cancer 2013, 22:2-12

4. Breuss JM, Gillett N, Lu L, Sheppard D, Pytela R: Restricted distribution of integrin beta 6 mRNA in primate epithelial tissue. J Histochem Cytochem 1993, 41:1521-1527.

5. Breuss JM, Gallo J, DeLisser HM, Klimanskaya IV, Folkesson HG, Pittet JF, Nishimura SL, Aldape K, Landers DV, Carpenter W, Gillett N, Sheppard D: Expression of the beta 6 integrin subunit in development, neoplasia and tissue repair suggests a role in epithelial remodeling. J Cell Sci 1995, 108:2241-2251.

6. Niu J, Gu X, Turton J, Meldrum C, Howard EW, Agrez M: Integrin-mediated signalling of gelatinase B secretion in colon cancer cells. Biochem Biophys Res Commun 1998, 249:287-291.

7. Agrez M, Gu XH, Turton J: The alpha v beta 6 integrin induces gelatinase B secretion in colon cancer cells. Int J Cancer 1999, 81:90-97.

8. Z Zhang ZY, Xu KS, Wang JS, Yang GY, Wang W, Wang JY, Niu WB, Liu EY, Mi $Y$, Niu J: Integrin alphanvbeta6 acts as a prognostic indicator in gastric carcinoma. Clin Ongol 2008, 20:61-66.

9. Tanaka H, Terada Y, Kobayashi T, Okado T, Inoshita S, Kuwahara M, Seth A, Sato $Y$, Sasaki S: Expression and function of Ets-1 during experimental acute renal failure in rats. J Am Soc Nephrol 2004, 15:3083-3092.

10. Ghosh S, Basu M, Roy SS: Ets-1 protein regulates vascular endothelial growth factor-induced matrix metalloproteinase- 9 and matrix metalloproteinase-13 expression in human ovarian carcinoma cell line SKOV-3. J Biol Chem 2012, 287:15001-15015

11. Hashiya N, Jo N, Aoki M, Matsumoto K, Nakamura T, Sato Y, Ogata N, Ogihara T, Kaneda Y, Morishita R: In vivo evidence of angiogenesis induced by transcription factor Ets-1: Ets-1 is located upstream of angiogenesis cascade. Circulation 2004, 109:3035-3041.

12. Zhengchuan $\mathrm{N}$, Jiayong $\mathrm{W}$, Jun $\mathrm{N}$ : Protein expression of elF4E and integrin av $\beta 6$ in colon cancer can predict clinical significance, reveal their correlation and imply possible mechanism of interaction. Cell Bioscience $2014,4: 23$

13. Ito $Y$, Takeda T, Okada M, Matsuura N: Expression of ets- 1 and ets-2 in colonic neoplasms. Anticancer Res 2002, 22:1581-1584.

14. Yang GY, Xu KS, Pan ZQ, Zhang ZY, Mi YT, Wang JS, Chen R, Niu J: Integrin alpha $v$ beta 6 mediates the potential for colon cancer cells to colonize in and metastasize to the liver. Cancer Sci 2008, 99:879-887.

15. Pap Z, Pavai Z, Denes L, Kovalszky L, Jung J: An immunohistochemical study of colon adenomas and carcinomas: e-cadherin, syndecan-1, ets-1. Pathol Oncol Res 2009, 15:579-587.

16. Ahmed N, Niu J, Dorahy DJ, Gu X, Andrews S, Meldrum CJ, Scott RJ, Baker MS, Macreadie IG, Agrez MV: Direct integrin avß6-ERK binding: implications for tumor growth. Oncogene 2002, 21:1370-1380.

17. Wang J, Wu J, Hong J, Chen R, Xu K, Niu W, Peng C, Liu E, Liu S, Agrez M, Niu J: PKC promotes the migration of colon cancer cells by regulating the internalization and recycling of integrin alphavbeta6. Cancer Lett 2011, 311:38-47.

18. Park YH, Jung HH, Ahn JS, Im YH: Ets-1 upregulates HER2-induced MMP-1 expression in breast cancer cells. Biochem Biophys Res Commun 2008, 377:389-394.

19. Chai Y, Chipitsyna G, Cui J, Liao B, Liu S, Aysola K, Yezdani M, Reddy ES, Rao VN: c-Fos oncogene regulator Elk-1 interacts with BRCA1 splice 
variants BRCA1a/1b and enhances BRCA1a/1b-mediated growth suppression in breast cancer cells. Oncogene 2001, 20:1357-1367.

20. Kavurma MM, Bobryshev $Y$, Khachigian LM: Ets-1 positively regulates Fas ligand transcription via cooperative interactions with Sp1. J Biol Chem 2002, 277:36244-36252.

21. Kim E, Gunther W, Yoshizato K, Meissner H, Zapf S, Nusing RM, Yamamoto H, Van Meir EG, Deppert W, Giese A: Tumor suppressor p53 inhibits transcriptional activation of invasion gene thromboxane synthase mediated by the proto-oncogenic factor ets-1. Oncogene 2003, 22:7716-7727.

22. Bates RC, Bellovin DI, Brown C, Maynard E, Wu B, Mercurio AM:

Transcriptional activation of integrin $\beta 6$ during the epithelialmesenchymal transition defines a novel prognostic indicator of aggressive colon carcinoma. J Clin Invest 2005, 115:339-347.

23. Liu S, Wang J, Niu W, Liu E, Wang J, Peng C, Lin P, Wang B, Khan AQ, Gao H, Liang B, Shahbaz M, Niu J: The beta6-integrin-ERK/MAP kinase pathway contributes to chemo resistance in colon cancer. Cancer Lett 2013, 328(2):325-334.

24. Peng C, Liu X, Liu E, Xu K, Niu W, Chen R, Wang J, Zhang Z, Lin P, Wang J, Agrez M, Niu J: Norcantharidin induces HT-29 colon cancer cell apoptosis through the alphabeta6-extracellular signal-related kinase signaling pathway. Cancer Sci 2009, 100(12):2302-2308.

doi:10.1186/2045-3701-4-53

Cite this article as: Peng et al:: Integrin av $\beta 6$ and transcriptional factor Ets-1 act as prognostic indicators in colorectal cancer. Cell \& Bioscience 2014 4:53.

\section{Submit your next manuscript to BioMed Central and take full advantage of:}

- Convenient online submission

- Thorough peer review

- No space constraints or color figure charges

- Immediate publication on acceptance

- Inclusion in PubMed, CAS, Scopus and Google Scholar

- Research which is freely available for redistribution 